contributed 296,666 and the Federal Government 890,000 dollars. Some time must elapse before the effect of these widely distributed schemes shows itself on the wild-life population, but there is every reason to think that the result will bo gratifying to the naturalist as well as to the sportsman.

\section{Television Transmission over Telephone Cables}

Is the Record published in October by the Bell Telephone Laboratories, Inc., I. Weis gives a helpful discussion of the problem of transmission signals over telephone cables. Most radio broadcasts originate in the studios of the broadcasting companies, and are transmitted thence to the radio stations over high. quality programme circuits. Not infrequently the 'pick-up' point is at a distance from the studio and circuits to the studio must bo provided over telephone 'cable pairs' not normally employed for broadcasting. With television broadcasts such remote pick-up points are also required, but the utilization of ordinary telephone circuits to link them to the telovision studio is more difficult because of the much wider band of frequencies omployed, besides certain exacting requiroments for telovision transmission. Because of the experimental state of television broadcasting at the present time, no arrangements for transmitting from these remote pick-up points have as yet been standardized.

LAST May an experimental circuit of this nature was provided for the National Broadcasting Company. More recently a somewhat similar ono was provided for the Columbia Broadcasting System. For ordinary telephone circuits a frequency band of about 3,000 eycles is sufficient, whilo for both these recent experiments the band extended from 45 to more than three million cycles-a range a thousand times greater than the roice band. When we consider the losses, we find that the loss in a co-axial cable at three million cycles is only one millionth that in a cable-pair of equal length. For satisfactory television transmission, equalizers must be provided to mako the overall loss essentially the samo for all frequencies. In addition to the variation in loss with frequency there is also a variation in the time of transmission. In television transmission, if this is not kept oxtremely small the detail of the picture will be blurred, and spurious transients and 'ghosts' will appear. Before a cable pair can bo used for television, it is necessary to know the transmission time and then to provide phase equalizers to correct it. In the experiments the equalized line maintains the same transmission time to within plus or minus one tenth of a microsecond, and this can be measured.

\section{Traffic Signals at 'Bank Complex'}

A Description is given in Roads and Road Construction of November 1 of the 'electromatic' vehicleactuated system operating on tho 'flexible-progressive' system. Automatic traffic signals outside tho Bank of England and on several important roads in the locality are to be installed as early as possible. It has been found that the signals in other parts of the
City have proved of such value during the black-out that police officers have been able to concentrate on other important duties, and it is only at a few intersections that it has been necessary for them to control traffic by hand signals. The name 'Banl: Complex' has been given to the area which is the junction of Threadneedlo Strect, Cornhill, Lombard Street, Fing William Street, Princes Street, Queen Victoria Street, Poultry and Mansion House Street. A specification for traffic signals to control the heavy and complicated traffic at this junction was prepared by the Ministry of Transport in collaboration with traffic officials of the City of London Police.

A SCHEste to meet the requirements of the specifica. tion was prepared by Automatic Telephono and Electric Co., Ltd., using electromatic vehicle. actuated signals. As traffic is approximately equally heavy in all directions, the problem is mainly concerned with ensuring the most rapid transit of vehicles through the thoroughfares converging on the area of tho Bank Complex. Traffic increases to a maximum at morning and evening periods, and, if congestion and traffic blocks aro to bo avoided, tho available road space must be used with the greatest officiency. The whole system will bo 'electromatic', operating on the flexible progressive system, under tho cont.ol of $a$ 'dual master-timer', and vohiclo detectors will bo used in each approach to the 'Bank Complox'. Signals are actuated by a special control unit divided into seven sections, which aro linked together to coordinate the signal phases. It is important to notice that right-of-way is given to an approach only if thero is a demand, and the length of this right-ofway period depends, up to a predotermined maximum, on the volume of the traffic. A novel fenture of this system is provision of necommodation for traffic assessors in Cornhill and Poultry to determine the volumo of traffic entering the complex on these approaches, so that variations of the right-of-way timo can be mado automatically.

\section{The International Seismological Summary}

THE International Seismological Summary for October, November and December 1933 has just been received. It deals with 123 epicontres for earthquakes which occurred during that quarter, of which 47 were new epicentres and 76 repetitions of earthquakes from old epicentres, thus again confirming the knowledge that earthquakes tend to recur from the same epicentres. Tho five earthquakes with abnormal focus during the quarter all had deop foci. The first was on October 25, with epicentro in the Andes_north-west of Jujuy (Argentine) with focus 0.03 of the earth's radius below normal. The second was on November 14 with epicentre north-east of Santiggo on the borders of Chile and the Argentine with focal depth 0.02 of the earth's radius below normal. 'The third was on November 19 in the Pacific Ocean off the Japanese coast nearly south of Tokyo with focal depth 0.035 of the earth's radius below normal. The fourth and deepest was on December 1 with epicentre in the Pacific Ocean immediately to the south of the island 